\title{
Aproximación á novela histórica na literatura galega. A Idade Media como tema
}

\author{
Manuli.a Ál.varez.
}

\section{ALGUNHAS PRECISIÓNS SOBRE O CONCEPTO DE NOVELA HISTÓRICA}

Contra todas as previsións dalgún dos seus primeiros e máis egrexios cultivadores' e mesmo do escepticismo de certa crítica, a novela histórica gozou desde a súa aparición dunha excelente saúde. Naturalmente, con altos e baixos, sendo habitual a asociación dun maior cultivo da mesma con épocas de crise política, filosófica e relixiosa.

O éxito evidente acadado nos últimos anos por este tipo de narracións suscitou, como non podía ser menos, o interese da crítica especializada, de xeito que neste momento dispoñemos xa dun importante corpus de traballos sobre o lema.

O concepto «novela histórica», pola ausencia de diferencias formais con outro tipo de narracións e polo hibridismo do seu discurso (mesturando historía e literatura), posúe uns límites imprecisos; se a isto engadimos a evolución experimentada na segunda metade do século XX polo propio xénero, na medida en que reflicte a consciencia actual das limitacións do propio coñecemento histórico, entenderemos por qué non existe unha definición satisfactoria do mesmo.

Desde o xa clásico traballo de Lukács sobre a novela histónica en xeral, ata o excelente estudio de Celia Fernández, sobre a narrativa hispánica². os

I Manzoni, por exemplo, prognosticaba a súa morte.

2 C. Fernández Pritio. Historia y novela: poéfica de la novela hisiórica. Pamplona, Eunsa. 1988. Este libro é froito da súa tese de doutoramento, defendida en Santiago de Compostela no 1995. 
intentos de acoutar o termo dan como resultado definicións que oscilan entre o vago «La novela historica es un subgénere numativo c"l cua construcción se inclayen determinados elementos y/o personajes históricoss. ${ }^{3}$ e o máis preciso de Harro Müller, recollido por Kurt Spang (1995: 64), "la novela histónica es una construcción perspectivista estéticamente ordenada de situaciones documentables a caballo entre la firctoin y la referencialidad. comstraction dirigida por un determinado autor a un determinado publices en un determinado momentor.

Como queira que sexa, o que si está claso é que, a estas alturas, o xénero debería entenderse non como algo estático e fixado dunha vez para sempre, senón como algo dinámico, que se vai contormando e polo tanto vai evolucionando co progresivo aumento do listado de obras que, de xeito máis ou menos explicito, amosan a súa vontade de adhesion, ou incluso de ruptura, co que poderiamos considerar as liñas esenciais do mesmo, presentes dun ou doutro xeito en todos os casos. Cómpre entendelo tamén na perspectivá comunicacional, tendo en conta a todos os que participan no proceso de comunicación: autores, lectores. intermediarios varios. Convén finalmente non esquecer a importancia que o paratexto ten na adscrición xenérica dunha obra, e como condicionante ou conductor da súa lectura.

A grandes trazos, nestes momentos distinguimos entre a novela histórica que segue o modelo clásico scotriamo, cunhas características xa sistematizadas, e a novela histórica postmoderna. transgresora e renovadora ó mesmo tempo.

En todo caso, os elementos en común son moito máis importantes que as diferencias, e poderianse sintelizar nos seguintes puntos:

- Mestura de discurso histórico e literario, de historia e ficción.

- Reconstrúese un pasado máis ou menos próximo ó presente da escrita, a partir dun discurso histórico previamente elaborado na súa totalidade ou parcialmente. Nesta reconstrucción, $o$ anacronismo é un compoñente amplamente utilizado, cunha ou outra finalidade.

- Na inmensa maioría dos casos, vaise ó pasado para incidir ideoloxicamente sobre o presente.

- Reclabórase ou invéntase en xeral sobre o que non está documentado historicamente: agás nalgún caso de novela postmoderna. onde se distorsiona a propósito o dato histórico, nun xogo tácito co lector.

- O lector ten un coñecemento previo, máis ou menos importante, de acontecementos, personaxes, etc. da novela. Establécese desde o principio o que se chama un pacto de lectura.

3 C. MArA, "Retrospectiva sobre la evolucion da la novela histórica», in K. SPANG et alii, La novela histérica. Teoría yomentarios. Pamplona. Eunsat, 1998, p 16. 


\section{SOBRE A ORIXE DA NOVELA HISTÓRICA}

É un feito comunmente aceptado que a novela histórica como xénero nace a principios do século XIX con Walter Scott. cuxa obra, pola extraordinaria influencia que cxerceu sobre a literatura europea da época, fixaría o patrón do mesmo.

Téñense apuntado narracións máis ou menos históricas como supostos antecedentes do xênero, xa que as relacións entre o discurso histórico e o literario son tan antigas como a propia humanidade, pero o seu perfil máis clásíco considérase un produclo decimonónico.

Varias son as circunstancias de tipo histórico-social que se esgrimen para explicar a súa aparición na literatura do sćculo XIX. Non quixera, pois, repetir o que é de sobras conecido: sen embargo, si me gustaría apuntar algo que probablemente botaría luz sobre o tema do seu nacemento e difusión: trátase da asociación da aparición da novela histórica coa creación do Estado liberal, do Estado-nación, que intenta xustificarse na historia e ofrece recreacións do pasado que xustifican a creación ou existencia do propio Estado na época actual.

$O$ pasado ten unha importancia extraordinaria para a autoidentificación da colectividade. Isto comprendeuse moi ben no século XIX en toda Europa, onde a cuestión da novela histórica se asocia co problema da identidade nacional; véxanse senón os casos de Alemaña, Italia, ou Inglaterra. Por poñer un exemplo, Wanhoe, probablemente a obra de Scott que máis éxito tivo, ata o punto de ser levada ó cine, está situada no século XII, cando os normandos dominaban Inglaterra, e comeza xa coa presentación do conflicto lingüistico entre francés e inglés; ć de notar que a obra viu a luz no momento en que se repetía o perigo de agresión por parte dos franceses, co propósito de Napoleón de invadir Inglaterra.

A propósito do caso de España, resulta moi interesante o libro do protesor norteamericano Inman Fox, dedicado, segundo as súas propias palabras, a «tın estudio del espiritu nacionalista y la concomitante construcción de una identidad nacional que nacen en España con el Estado liberal hacia mediados del siglo $X I X, 4$.

Esta circunstancia, se ben foi xeralmente desatendida pola crítica, a xulgar polo pouco ou nada que se menciona, non lle pasou en absoluto desapercibida a Celia Fernández, para quen este tipo de novela cumpre un destacado papel no sistema cultural e literario do Romantismo español, na medida en que, entre outras moitas cousas, eintenta llenar el vacio historiográfico existente sobre el pasado de España para contribuir a conformar una idea de nación. una identidad nacional»(1998:99, e cita a Jon Juaristi).

4. Fox, La invención de Esspana, Madrid. Cátedra, 1997, p. 11. 
Noutra ocasión, a propósito da novela histórica actual, a mesma autora volve sobre o tema para afirmar que "El género lque ofiere muchas líneas y tendencias) no pretende forjar un pasado histórico a la medida de la mora clase en el peder, como ocurría en el Romanticismo, s.

Non se discute xa a carga ideolóxica das novelas históricas; mesmo constitúe unha marca xenérica. $O$ escritor recrea unha determinada etapa histórica co obxectivo máis ou menos explícito de incidir ideoloxicanente no presente. Isto como se sabe é válido mesmo para aqueles productos máis aparentemente inxenuost.

\section{A NOVELA HISTÓRICA NA LITERATURA GALEGA. APARICIÓN E FORTUNA DO XÉNERO}

Polo que fai ó caso concreto da literatura galega, naturalmente que a aparición do xénero ten unha clara motivación ideolóxica, directamente relacionada coa creación do Estado liberal español.

Non esquezamos que o espertar da conciencia nacional prodúcese en Galicia como reacción á famosa división provincial de Isabel II (1833). Este feito considérase, como é natural, un auténtico alentado contra a liña de flotación do país, na medida en que borra aquilo que formalmente o distingue cono a unidade que viña sendo desde a época dos romanos: a partir de agora, ignórase a tradicional división en comarcas e, a efectos administrativos, deixa de ser o Reino de Galicia para converterse en 4 provincias doutro reino. A reacción foi Ian forte que deu nome ó primeiro movemento deste signo, chamado Provincialismo. En Galicia, pois, prodúcese unha reacción defensiva cando se observan accións que constitúen unha agresión contra a unidade do país.

Este é se cadra o feito máis rechamante, pero non é o único; a el hai que sumar a cuestión da lingua, único vehículo de comunicación de máis do $90 \%$ do país, constreñida ó nivel oral por unha lexislación abusiva?. e fronte á cal non hai moita capacidade de reacción pola xeral ignorancia que existia nese momento a cerca do pasado histórico e cultural do país por parte do escaso grupo social alfabetizado. En Galicia o analfabetismo superaba ó do resto do Estado (que rondaba o $75 \%$ ); por outra parte esta alfabelización dáse en castelán ou en latín, nunca en galego. Por esta razón, a reivindicación da súa dignidade converterase de agora en diante en bandeira do galeguismo.

5 C. FFRNANDLZZ, "Relaciones pasado-presente en la namativa histórica contemporánea», in Romrra Castillo et alii, La nenela histónica a finale's del siglo XX, Madrid. Visor. 1996.

- Que A. Dumas publique (s tres mosqueteiros cando en Francia se estaba a debater sobre o réxime político (absolutismo-liberalismo) do país, non é casual nin inocente.

7. Garcia Negro, O galego e us lejs. Aproximarión soriolingüistica. Edjcións do Cumio. 1991. O libro é resultado da súa tese de doutoramento, presentada en Santiago no 1991. 
Agora ben, de momento temos un país ágrafo na súa lingua, con dificultades tamén para a lectura: por iso non é de estrañar que as primeiras novelas deste xéncro que recrean o pasado de Galicia non se expresan en galego: vêxase, senón, Gelmirez, de Murguía. Haberá que agardar ata finais de século para que agrome un público lector de novelas nesta lingua, xusto cando López Ferreiro publica as súas: antes houbo só algún intento moi tosco e cun valor eminentemente arqueolóxico. Ó Rexurdimento, fundamentalmente poético. c como parte do seu carácter de elemento sine qua non da nosa recuperación nacional, débeselle apuntar a creación dese público lector.

Así pois, coa publicación en 1894 de A tecedeira de Bomaral, López Ferreiro inaugura un xénero na nosa literatura, que se consolidará no século $X X$, nunha evolución, en liñas xerais, similar á que se produce no noso contorno europeo ${ }^{8}$. E isto a pesar da especial circunstancia dunha literatura non oficial ata 1978 (coa aprobación da Constitución), e da propia carga ideolóxica desta modalidade narrativa, xa que intenta recuperar unha realidade negada ou falseada pola historia oficial, coa que entra en pugna aberta, e que é mirada de esguello c con receo por parte dos sectores institucionais.

Naturalmente, se nos fixamos nas datas de publicación. observamos como coinciden os períodos, e como aqueles nos que abunda a novela histórica se caracterizan á súa vez por unha maior tolerancia e respeto polas liberdades públicas\%. Efectivamente, Galicia vive unha etapa expansiva e de consolidación da súa cultura, promovida polas Irmandades da Fala, o Grupo Nós, e o Seminario de Esludos Galegos, coincidindo co período europeo de entreguerras. Vai ser cando un dos membros máis egrexios do Grupo Nós, Ramón Otero Pedrayo, publique as súas novelas históricas. Dos camiños da vida (1928) e A romeiría de Xelmirez (1934). O levantamento mililar do 36, e a represión que trac consigo. truncan o normal desenvolvemento da nosa vida cultural e polo tanto da literatura. que retorna á vida timidamente á través da poesía: ata 1951 non se publica a primeira novela en galego, A xente da Barreira (1951), de Ricardo Carballo Calero, onde se narra a saga dunha familia fidalga, desde o seu enriquecemento ata a súa decadencia coa ascensión da burguesía. O tema, un intento de recuperar parte da nosa memoria histórica, establece unha ponte con Nós, a través do que foi un dos temas recorrentes de Otero Pedrayo, a decadencia da fidalguía.

O final da dictadura, coa morte de Franco en 1975, e o paso ó réxime constitucional traen aires renovadores 6 país. A aprobación da Constitución, a pro-

8 Non estamos establecendo unha comparación numérica, que sería absurda. senón comprohando como a nosa literatura vai evolucionando e latexando (anyue sexa debilmeste) dun xeito similar e en parale lo co resto da eutopea (polo menos).

- Outros prefiren falar de periodos de crise (véxase, por exemplo. Kurt Spang c Carlos Malla. opus cit.. pp. 9 e 20 respectivamente). Creo que é unha cuestión de perspectiva: para nós son etapas de formación e crecemento do nacionalismo: para outros son etapas nas que se cuestiona o modelo de Estado, polo menos no caso de España. 
mulgación da Lei de Nomalización linguística, a introducción do gilego no ensino, etc, ofrecen esperanzas a un mereado editorial incipiente, que demanda unha maior e máis diversificada producción. especialmente no eido da narrativa, moi deficiente ata ese momento. Para estimulala créanse unha serie de premios: premio de narrativa curta Modesto R. Figueiredo( 1976); os instituídos polas editoriais Galaxia (1975) e Xerais (1984), ou o Blanco Amor (1981). promovido desde os concellos (todos tres á procura da novela longa, unha carencia que se vive daquela como unha frustración), etc.

Deste xeito, a década dos 80 vai asistir a un auténtico florecemento da novela, publicándose máis títulos nestes anos que en todo o período anterior. Amplíase considerablemente o abano xenérico, empézanse a traducir os clásicos da literatura universal e desaparecen os autores consagrados 10 , sendo substituídos por novas promesas narradoras (moitos deles anteriormente poetas), que o paso do tempo decantaría.

Como non podía ser menos, a partir de agora, e ala a actualidade, a novela histórica vai ser cultivada con éxito, a xulgar pola cantidade e calidade dos títulos publicados. Este fenómeno, ó meu modo de ver, corre paralelo ó propio ascenso do nacionalismo e á reivindicación da historia de Galicia por parte dos historiadores (fronte á historia oficial, na que esta practicamente desaparece). Así pois, historiadores e escritores de novelas históricas darían resposta ó degaro social polo conecemento do propio pasado (que se sente furtado), e a súa recreación.

\subsection{A IDADE MEDia como tema}

A percepción clara do Medievo como berce da Europa contemporánea, e quizais a idealización romántica dun mundo tan afastado e próximo á vez. explicarían moi probablemente o éxito deste tema na novela histórica europea do XIX

Polo que se refire ó caso concreto da literatura galega, a Idade Media exerce sobre nós unha innegable fascinación, polo que hai de descubrimento dunha realidade agochada pola historiografía oficial, a conseguinte e natural necesidade da súa recreación, e a nostalxia pola súa condición de paraíso perdido da normalidade política e social, fronte á frustración actual. Desde os comezos mesmos constitúe sen ningunha dúbida o tema preferente (véxanse as novelas de López. Ferreiro, por poñer un exemplo), e nos últimos vintecinco anos domina por completo esta modalidade narrativa.

10 Blanco Amor morre no 1979, Cunqueiro no 198! (por poñer os dous casos máis sobranceiros). 
Se bolamos unha rápida ollada ó listado de títulos, observamos cómo o interese dos escritores xira fundamentalmente ó redor de dous personaxes. o rei D. García e o bispo Xelmírez. e a revolta Irmandiña.

O rei D. García exerce un especial atractivo romántico polas súas peculiares circunstancias biográficas, así como polo feito de algúns ver nel unha especic de símbolo do propio reino de Galicia. Fn ocasións forma parte do telón de fondo, así, por exemplo, X. Bernárdez Vilar sitúa no seu tempo $N o$ amo do cometa (1986); outras. mesmo ultrapasa o xénero. como sucede coa xa citada obra de Manolo Rivats, onde aparece metamorfoseado nun corvo branco, rodeado dun exército doutros 300 corvos. estes si, negros coma chamizos 11 . Pero quen verdadeiramente reivindica a súa memoria é Darío X. Cabana, converténdoo en protagonistat absoluto de Morte de Rei (1996), sen dúbida unha das mellores novelas históricas da literatura galega ata o de agora. A obra, que comeza cun primeiro plano do rei só, cangado polas cadeas e fisicamente acabado por unha reclusión tan prolongada. móstranos o decorrer vital e a dramática fin dun personaxe en cuxa caracterización psicolóxica percibimos claramente a pegada shakespeariana. A utilización do contrapunto e oflash back permitenos asistir ás últimas horas do rei e seguir a súa peripecia vital desde a infancia ata o momento presente. O contraste entre o paraíso perdido da liberdade ou dos triunfos doutrora. e a presente tan adverso, fai ainda máis dramáticas estas horas finais. nas que o protagonista, atormentado polos recordos do reino perdido e a traizón dos seus ismáns. vai gán̆ando en profundidade psicolóxica a medida yue alvanza a narración. O resultado é un retralo con forza, a pesar do franciscanismo un tanto inverosimil c anacrónico.

A obra, atravesada toda ela dun alento Épico. quere ser fiel o dato histórico: dátanse con precision os aconlecementos. e inclúese ó final un censo de personaxes no que o alutor non só distingue os de ficción dos de probada exisrencia histórica, senón que, nun alarde de erudición, pon en evidencia certas falsificacions intencionadas de historiadores espanois ou portugueses. Con todo, non podemos perder de vista que se trata dunha obra de fieción. na que se inventa sobre todo aquilo do que non se ten constancia histórical2. Estamos diante dunha novela e como tal debe ser lida.

Xelmírez, pola súa parte. protagoniza a novela histórica de Otero Pedrayo. A romeiria de Xelmíré nal que o bispo peregrina a Roma para solicilar do Papa o palio arcebispal. En Magog(1997), María Gándara dálle un papel xa máis secundario.

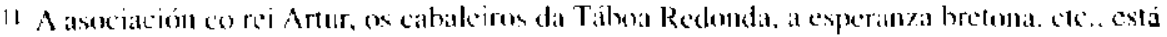
clara. Da lenda da suponal metamorliose do rei Anur en corvo faise eco R.S.I.oosis en a The

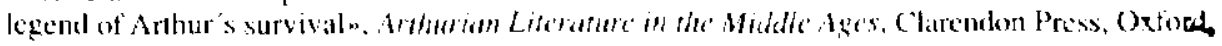
1969.

12 Por poñer un exemplo: nit novela o rei pide ser concerrado coas cadeas, pero disto pon tam mingunhat constancia documental. 
A revolta irmandiña aparece tratada por X. Bernárdez Vilar en Un home de Vilamedin. Anatomia da rewolución irmandiña) (1975). Un caso especial constitúco Historia don paraugas azul (1991). de Xosé Miranda, na que un narrador-personaxe, ante a inminencia da súa morte, escribe nun caderno os acontecementos vividos por el, na esperanza de que alguén atope o manuscrito e así quede constancia dos feitos relatados; deste xeito conecemos as actividades dos firsyuenllos no verán de 1469. Sen dúbida o máis destacable desta obra (á que habería que considerar máis que unha noveda histórica, unha fantasía histórica), é o seu carícter postmoderno e subversivo. Efectivamente, toda cla é un xogo paródico e intertextual, unha subversión consciente das regras da verosimilitude positivista $A$ situación temporal (tempo dos Nimónides) é imaxinaria, pero todo apunta á ldade Media (utilizase o sintagma El Rei, os epigrafes dos capitulos poderían recordar os das narracións medievais). A localización espatcial, sendo ficticia tamén (Liunamore 1.3 e arredores), correspóndese claramente con Lugo e boa parte do que hoxe é a provincia. O anacronismo é unha práctical comslante (fálase dun trobador chamado Cunqueiro: alúdese a Margaret Thacher: dise que daquela a cidade de Liunamore estaba gobernada polo tirano Cartracha Parda a alusión a Cacharro Pardo é obvia; xógase co topónimo Fraga e o nome do actual presidente da Xunta . etc.). Utilizase umba determinada versión da revolta irmandiña, pero distorsiónase conscientemente (cóntase o asalto a Lugo, que nunca sucedeu: a loita irmandiña preséntase como un conflicto mundo rural-mundo urbano, cando xa está historicamente probado que ela mesma foi un fenómeno claramente urbano. etc.). Con todo, e a pesar do evidente predominio do elemento fantástico (to do o relativo ós paraugas), queda clara a vontade de recrear uns dados acontecementos históricos. O xogo intertextual coa literaturat galega e universal queda patente cando se fala do poeta Virxilio como dun meigo inventor do paraugas, ou do toco Malevín. patrón dos camiñantes e extraviados (Malevín. o Merlín de Cunqueiro. recolleu a calzada Astúrica-Augusta enrolándoa como se fose unha alfombral: fálase do Simbad. ó que se lle concede credibilidade, un estatus superior ó de historia de aventuras: introduce o estribillo da conecida cantiga medieval, «Lelia doura», como se fose una canción dos bárhares cantada tamén polos homes do Oeste. etc.. En fín. toda a novela é un continuo xogo co lector, que se ve arrastrado a unha desconcertante e allucinadal viaxe intelectual, na que oposicións como presente-pasado ou Historia-realidade-lieción quedan absolutannente neutraliradis.

A Idade Media como escenatio. o propio imaxinario literario medieval, ou personaxes de probada existencia históricat nesta épocal. aparecen en numerosats obras de ficcion. sen que poidamos falar neses casos de "novelas historicas", senón doutras modalidades narrativas que incorporan algún destess elementos.

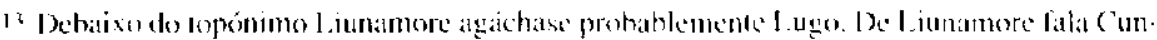

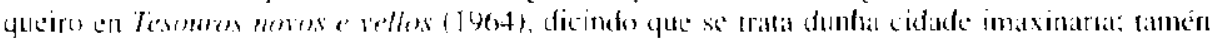

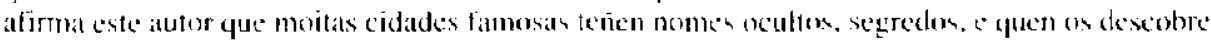
fasise dono dat cidlade ou retins en cosc:siom. 
É o caso de. por exemplo, En salvare compaña, de Manolo Rivas. onde se menciona o rei D. Garcia; Cándido Branco é Cabaléro Negro, na que Dario $X$. Cabana constrúe unha utopía que sitúa nesta época como o polía estar noutra; ou Galián en Sarr, do mesmo autor. cuxo protagenista é un cabaleiro dat Mesa Redonda. Agora ben, en todo caso, constitúen unha proba do atractivo do tema. cuxo éxito obviamente non obedece só a razóns "intrhas". senón que coincide co experimentado noutras literaturas neste momento, e seguratmente se ve favorecido polo éxito de best sellers como o nome de resade de U. Eco. etc. 